\title{
Activity-Based Costing
}

\author{
Faryan Jalalabadi, MD, BBA ${ }^{1} \quad$ Allen L. Milewicz, MD² Sohail R. Shah, MD, MSHA ${ }^{2} \quad$ Larry H. Hollier, Jr., MD ${ }^{1}$
}

Edward M. Reece, MD, MBA ${ }^{1}$

${ }^{1}$ Division of Plastic Surgery, Jamail Specialty Care Center, Baylor College of Medicine, Houston, Texas

2 Department of Surgery, Baylor College of Medicine, Houston, Texas

Address for correspondence Edward M. Reece, MD, MBA, Division of Plastic Surgery, Jamail Specialty Care Center, Baylor College of Medicine, 1977 Butler Blvd., Suite E6.100, Houston, TX 77030

Semin Plast Surg 2018;32:182-186. (e-mail: edward.reece@bcm.edu).

\begin{abstract}
Keywords

- activity-based costing

- accounting

- health care

Cost allocation for health care professionals can be an enigma within the health care system. Activity-based costing ( $A B C$ ) is an accounting tool that allocates costs incurred through a company's practice of providing goods and services to the consumer. $A B C$ can provide insight into inefficiencies across the supply chain and unlock excess capacity. This, in turn, can drive services provided toward generating more value for the hospital system. $A B C$ can be tailored to focus upon a unit of measurement that holds value as it pertains to production. With time-driven $A B C$ (Td-ABC), we look to use the advantages of both the fee-for-service and capitation model to transition to a valuebased system. Providers are rewarded based on efficiencies and successful outcomes in patient care while disincentivizing poor outcomes and superfluous volume/expenditures. $A B C$, however, does not come without its own risks and disadvantages, and the user must exercise caution in applying this cost-allocating tool to avoid detriment to its practice. A review of the literature was conducted to analyze the implementation, medical application, and advantages and disadvantages of Td-ABC.
\end{abstract}

Activity-based costing $(A B C)$ is an accounting tool that allocates costs incurred through a company's practice of providing goods and services to the consumer. ${ }^{1}$ In health care, this is often based on services associated with patient care, which can be procedural or time-based. These include indirect costs, such as overhead expenses, and also direct costs associated with a given clinical or business entity, such as costs attributed to a given procedure from the expenses of the operating room. ${ }^{2}$ In most firms, direct costs are not allocated.

The accounting method can be tailored to focus on a unit of measurement that holds value as it pertains to the company's production method. This revolves around the tasks that are performed during the production process. This unit of measurement can fall under the metric of time or space-given the minutes required for a procedure, the square feet associated with a given production, or even the quantity of megabytes used for a given level of service from the standpoint of computer data. The challenge of applying $\mathrm{ABC}$ is in deciding which unit of measurement makes the most sense in telling the story of cost drivers for that given service. $^{3}$ If appropriate metrics are identified, the $A B C$ method provides insight as to whether services provide enough value to customers and can serve as a roadmap to decide where strategic assets should be deployed.

In a medical setting, the production method could be envisioned as the completion of a surgery, procedure, or clinical intervention, with the outcome as a benefit to the patient. This is usually paired with a payment for the given service that is a representation of the value. One method of obtaining information regarding the unit being measured is to survey employees directly involved in the production. ${ }^{4}$ The individuals can provide subjective estimates for the percentage of time required to complete tasks along the production chain. The electronic medical record can greatly impact the process by more accurately estimating time. Alternatively, examining time for surgery, time for the procedure, and time for workup in the emergency department can also help provide an estimate of a facility's overall capacity to provide that service as a value to the patient. ${ }^{3}$
Issue Theme Business and Technology; Guest Editor: Edward M. Reece, MD, MBA
Copyright $\odot 2018$ by Thieme Medical Publishers, Inc., 333 Seventh Avenue, New York, NY 10001, USA. Tel: +1(212) 584-4662. ISSN $1535-2188$. 
When considering a given service as a production line (e.g., the process of completing a surgery through the perioperative environment), the patient must see the provider preoperatively, arrive for surgery, and comply with follow-up care. All steps require time and are associated with their own direct costs as well as indirect costs (such as administrative or marketing costs) related to the process. Across this theoretical surgical production line, the investigator can identify the cost of each section per unit time and subsequently calculate estimated cost drivers of the given service. ${ }^{3}$ Once a cost driver is calculated, it can be applied to future production estimates by applying models of the known to the unknown. Perhaps, more powerfully, it can also help identify areas of efficiency within the process being studied. Although it may be impossible to simplify patient care and hospital operations into concrete assembly line production, there is a benefit to calculating the costs of as many parts of the process possible using $\mathrm{ABC}$. Through the breakdown of as many parts possible, one can pinpoint which aspect of care is contributing it highest and lowest margins. Furthermore, time-driven $A B C(T d-A B C)$ can be used to identify where efficiencies may be gained within that production line such that our unit cost per time value can be reduced, decreasing the cost while increasing the value. ${ }^{5}$ In other words, Td-ABC can help identify excess capacity in the system upon which gains can be made to drive the value of a given service to the patient, the system, and third-party payers. ${ }^{6}$

In the production industry, $\mathrm{Td}-\mathrm{ABC}$ has provided cost-andprofit enhancement opportunities by identifying unprofitable customer relationships, unprofitable processes, and influences in product design and portfolio products. Td-ABC lends itself to applying these same virtues across medicine and within the hospital system. ${ }^{7}$ In other words, service lines may need to be reprised more competitively, either higher or lower, based on the revelation of value to the organization. In health care, Td-ABC can help in understanding and identifying contribution margins; however, it is unlikely to help eliminate service lines that are loss leaders, given that physicians must provide appropriate care to patients requiring low margin procedures. Nevertheless, it can unlock the identity of higher-margin services and promote these services, offsetting losses incurred and enabling a sustainable practice-one that can continue to serve people in need.

Time-driven $\mathrm{ABC}$ has been heralded as a tool by which the health care sector can transition from a fee-for-service type model to a value-based model. ${ }^{7}$ If it is possible to identify the value that a given service line procedure or department is offering through analysis with $\mathrm{Td}-\mathrm{ABC}$, presenting this value to a third-party insurance provider should have an impact on the quality experienced by the patient receiving surgery. ${ }^{8}$ Applying this approach with multiple iterations and to different service lines, a given organization or service line could approach a third-party payer and demonstrate the value and quality of the institution. This should result in better contracts and increased patient flow from the thirdparty payer to the hospital system. ${ }^{9}$ Yu et al at Texas Children's Hospital demonstrated success in applying Td$\mathrm{ABC}$ to the workup and treatment of appendicitis/appen- dectomy patients-a $17 \%$ reduction in costs when compared with the standard relative value units approach. Process mapping, as shown in -Fig. 1, links time encounters to identifiable steps of a hospital encounter to analyze areas of inefficiency. Similarly, Kaplan et al at the Cleveland Clinic reported a $10 \%$ reduction in costs for heart valve surgeries. ${ }^{10}$

Most health care professionals understand the current system of fee-for-service transactions in the health care field. Typically speaking, a given service is provided to the patient and is transacted with a fee. This is a clear and concise way of allocating value back to a service. The system inherently rewards the providers for delivering service based on volume; more service provided results in more payment delivered. ${ }^{6}$ The drawback of this system remains that there is no built-in disincentive from scaling service that may come at the sacrifice of quality. In this incentive structure, quality is not a necessary driving component. The payment parties have no accounting back for the quality of the service rendered, only that the services were indeed provided and therefore payment must be remitted. ${ }^{11}$ The more procedures provided the more payment received. This service model has a tendency to escalate costs without having to define quality. A study by Zuvekas and Cohen found that $95 \%$ of all physician office visits in 2013 were billed under a fee-for-service model. Since that time, the U.S. Department of Health and Human Services has seen a transition away from the fee-forservice model, although it remains the majority modality. ${ }^{12}$ From the patient perspective, it is not uncommon to hear about hyperinflated bills and exaggerated costs associated with a procedure, hospital, personnel, or device used. The litany of patients dissatisfied with their outcomes yet facing bankruptcy from colossal hospital bills is staggering.

Another system currently in the U.S. health care system is the capitation model. The members of the health care system that participate in the capitation model have a set fee that is allotted to provide service, yet services are capitated for pricing that is delivered from a top-down hierarchy. A decision is made at an executive level, as to how much money will be deployed for given services and how much those given services are valued at. Incentive stems from decreasing use. ${ }^{13}$ As a result, more of the membership payment is retained by the organization. Decreased use, however, can lead to denial of care, which has no disincentive in this model. The incentive for quality is delivered only through the perceived quality that the membership has of that organization. The argued benefit is health care cost containment as the driving incentive and not necessarily defining quality offered. ${ }^{14}$

In a value-for-care system, it has been suggested that a single "bundled" payment be given for that particular service. A bundled payment is defined as the reimbursement of health care providers on the basis of expected costs for clinically defined episodes of care. ${ }^{15}$ It can be used in a variety of specialties and is best suited in those where a systematic approach to care that can be reproduced universally. Given high-quality outcomes, the system is rewarded by a single bundled payment. ${ }^{16}$ If complications arise, or decreased efficiency is encountered, the system is penalized 


\section{Phase of Care: Emergency Room}

270 minutes

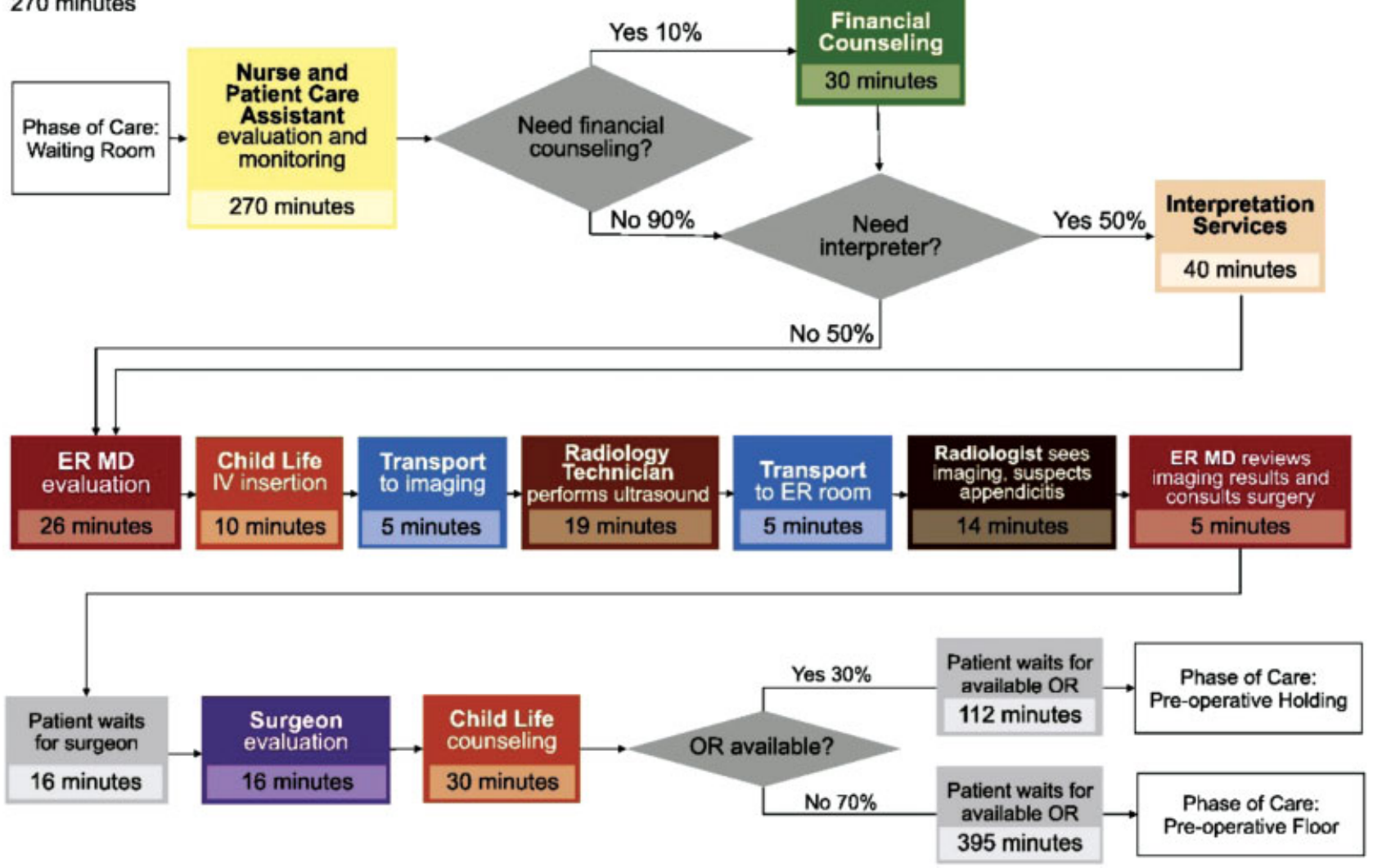

Fig. 1 Breakdown of time-per-step in the emergency room workup of appendicitis (Texas Children's Hospital). Boxes represent activities, with arrows indicating sequence. Colors correspond to personnel categories. ${ }^{10}$ ER, emergency room; IV, intravenous; OR, operating room.

under value-based medicine, and the health care organization bears the risk for the variance. The bundled payment rewards systems that can encourage the delivery of reliable, high-quality services while deterring entities from molding into a system that can simply accommodate volume irrespective of the value added. Value-for-service reimbursement advocates a system that creates self-governing feedback, thereby ensuring maximum reward to both patient and institution. ${ }^{17}$ In 2013, it was estimated that one-third of all health care reimbursements in the United States used bundled methodology. ${ }^{18}$ Although this concept already exists in health care, we believe that a ground-level view will help encourage physician onboarding.

In an ideal system, the risks of both the fee-for-service system and the capitation model would be minimized while the benefits would be maximized. This is the promise of a value-based delivery system where hypothetically highquality outcome services are provided in a way that incentivizes necessity of surgery around that episode of care. A major driver in the creation of this value-based system has centered on $\mathrm{ABC}^{7}$ Indeed, $\mathrm{ABC}$ has been allotted a major driver on the road to successful implementation of the valuefor-service health care plan. ABC allows the hospital system to identify, with a higher degree of precision, the actual costs to deliver a service. This enables the hospital to approach a third-party payment system with a high-quality marker for a lower price, thereby not only containing the cost but also delivering higher quality care. ${ }^{9}$ We must be cautious, however, in approaching value-based medicine through the lens of Td-ABC. It does not come without its own limitations.

One of the limitations is shown within calculating capacity. It is common for employees to erroneously report tasks directly related to production take up $100 \%$ of their capacity. This often neglects idle time, which includes travel time, training, breaks as well as pauses between cases, and case turnovers. Accurate times for a given service can be drastically overestimated, which can result in an overestimated cost driver. ${ }^{8}$ There are measures that can be applied to estimate practical capacity: some argue that $20 \%$ of reported capacity accounts for idle time. This standard leaves a large margin for error that may not reveal itself until after the point for which decisions must be made and relied on from the models created by Td-ABC. ${ }^{3}$ This is especially true when it applies to medicine as well as creating business cases for third-party payers. Furthermore, applying Td-ABC in an industry that historically operates on a small margin (health care and hospital systems estimated as low as eight percent) does not come without risks. ${ }^{19}$ There is a risk that the leadership may not have the appetite to experiment with given limited resources. ${ }^{16}$ To paint an accurate picture of value in a given production line is significantly demanding in terms of time and cost. To create and maintain the Td-ABC model in and of itself may require a dedicated budget line item and its own devoted capital expenditure. 
Another potential weakness in applying Td-ABC to our current marketplace in light of the Affordable Care Act is the changing landscape of third-party payers and the value that is perceived by them. An example of this would be a national insurance company who has changed its business model from seeking health care services for its members to acting as a health care brokerage that transacts its members to other medical insurance companies. Though complicated, the impact of this is striking: the third-party insurer who the health care system has assumed would value and seek quality care at the lowest costs (value for service vs. fee for service) is now in a position as a broker and may value simply the transaction of connecting a patient to a tertiary health insurer. ${ }^{16}$ Value for service may have become transaction for service that is reminiscent of the Enron era. The stage has been set for large health care insurance houses to lower their risk rather than looking for value within that delivery of care. Thus, the transition of the marketplace using Td-ABC to show value may fall upon deaf ears and will not be an effective freestanding tool on the road to a value- and quality-based model for health care.

Activity-based costing typically has been applied to repetitive processes that are fairly predictable in their outcomes such as manufacturing. In medicine, procedures such as total joint replacement lend themselves nearly seamlessly with this model. To understand the parts necessary to provide a given service requires some time interviewing the people who are delivering that service. For instance, interviewing a nurse to understand the amount of labor time it takes to bring a patient with appendicitis from the emergency room to the operating room. Furthermore, what is the measure of "idle time" where services lagged to be delivered? Was this due to excess capacity or due to inefficiencies in the system? Can those inefficiencies be worked out? Herein lies a hidden tool within value-based costing. In uncovering the time associated with known activities in a service line, the manager finds out how and why it takes a certain amount of time in different phases along the value chain. ${ }^{20}$ This reveals crucial information:

\section{- Is there excess capacity?}

- Where are the inefficiencies?

Understanding the preceding two metrics alone can have a profound impact on health care systems cost and may be cornerstones for delivering the "bundled" payment. ${ }^{7}$ Specifically, the cost of unused capacity has a greater value in the bundled payment system when it is realized why high dollar value employees such as physicians and nurses have time that is running idle when it could be applied to productive activity.

It is estimated that up to $70 \%$ of costs in the hospital are for personnel, and therefore identifying opportunities to decrease the costs of unused capacity would theoretically improve the contribution margin for the hospital typically running under $8 \%{ }^{9}$ Applying $\mathrm{ABC}$ could not only show the activity cost of a given service but perhaps, more importantly, could also show areas of inefficiency and excess capacity. Regardless of whether a given system believes in value-based medicine and bundled payments, $A B C$ as an enterprise commitment from the executive suite shows a considerable value of not only strategic decision-making but also activity improvement and cross-containment. When applied to a process, $A B C$, though consuming resources itself, can help enlighten the executives as to which services are associated with the lowest cost. ${ }^{16}$

In identifying why there is excess capacity and coupling that with net payments for the lower cost services, strategic decisions can be made to fill idle capacity with cases that have greater margin, thereby enhancing the overall profit of the health care system. This will be critical to executive teams making budget decisions to strategically deploy resources. It is important that staff, as well as administrative leadership, understand the value of $A B C$ in identifying rational decisions for sustainability. ${ }^{3}$

Allocations of costs are important in the accurate assessment and application of Td-ABC. Cost allocation for health care professionals can be an enigma within the health care system. Kaplan and Porter have argued that the costs for goods and services provided in health care are determined by realized reimbursements of the past. ${ }^{16}$ In their 2011 article, How to solve the cost crisis in health care, they state that "the inability to properly measure cost and compare cost with outcomes is at the root of incentive problem in healthcare and has severely retarded the shift to more effective reimbursement approaches." ${ }^{16}$ In delivering health care, the focus for medical providers is patient outcome above all. Adhering to this mandate while concurrently applying $\mathrm{Td}-\mathrm{ABC}$ can provide better insight into the cost required to produce optimal outcomes. What we can argue as a clear benefit of Td-ABC in our current health care landscape, is the ability of this costing system to identify inefficiencies in a given production line, thereby identifying opportunities to provide further benefit and value to the patient throughout the health care system. This clearly rolls into the bottom line in creating a more streamlined and resonant value proposition.

Regardless of the condition of reimbursement, using Td$A B C$ as a method for uncovering inefficiencies will help the delivery of care. ${ }^{11}$ This may subsequently help set the cost structure among many of the players in health care delivery and therefore impact the health care ecosystem. It is our suggestion that we must not overlook the flaws of this accounting system yet use its strength to improve the model of health care. ${ }^{9}$ Therefore, we encourage the application of this method broadly; however, in the indications for its use, we issue a caution so that the tool may be applied toward health care's advancement and not to its demise.

\section{References}

1 Kaplan RS, Witkowski M, Abbott M, et al. Using time-driven activity-based costing to identify value improvement opportunities in healthcare. J Healthc Manag 2014;59(06):399-412

2 Najjar PA, Strickland M, Kaplan RS. Time-driven activity-based costing for surgical episodes. JAMA Surg 2017;152(01):96-97

3 Noreen E, Brewer P, Garrison R. Managerial Accounting for Managers. New York, NY: McGraw Hill; 2014:203-265

4 Argyris C, Kaplan RS. Implementing new knowledge: the case of activity-based costing. Account Horiz 1994;8(03):83-105 
5 Kaplan RS, Anderson SR. Time-driven activity-based costing. Harv Bus Rev 2004;82(11):131-138, 150

6 Kaplan RS, Porter ME, Frigo ML. Managing healthcare costs and value. Strategic Finance 2017;98(07):24-33

7 Kaiser LS, Lee TH. Turning Value-Based Health Care into a Real Business Model. Harvard Business Review. Available at: https:// hbr.org/2015/10/turning-value-based-health-care-into-a-realbusiness-model. Accessed August 2018

8 Kaplan RS. Value-Based Health Care: Reconciling Mission and Margin. Harvard Business Review. Available at: https://hbr.org/ webinar/2015/11/value-based-health-care-reconciling-missionand-margin. Accessed August 2018

9 Kaplan RS, Witkowski ML. Better Accounting Transforms Health Care Delivery. Account Horiz 2014;28(02):365-383

10 Yu YR, Abbas PI, Smith CM, et al. Time-driven activity-based costing: a dynamic value assessment model in pediatric appendicitis. J Pediatr Surg 2017;52(06):1045-1049

11 Kaplan RS, Feeley TW, Witkowski ML, Albright HW. Intelligent Redesign of Health Care. Available at: https://hbr.org/2013/10/ intelligent-redesign-of-health-care. Accessed August 2018

12 Zuvekas SH, Cohen JW. Fee-for-service, while much maligned, remains the dominant payment method for physician visits. Health Aff (Millwood) 2016;35(03):411-414
13 Porter ME, Lee TH. The Strategy That Will Fix Health Care. Harvard Business Review. Available at: https://hbr.org/2013/10/ the-strategy-that-will-fix-health-care. Accessed August 2018

14 Porter ME, Kaplan RS. How to pay for health care. Harv Bus Rev 2016;94(7-8):88-98, 100, 134

15 Miller HD. From volume to value: better ways to pay for health care. Health Aff (Millwood) 2009;28(05):1418-1428

16 Kaplan RS, Porter ME. How to solve the cost crisis in health care. Harv Bus Rev 2011;89(09):46-52, 54, 56-61 passim

17 Haas DA, Kaplan RS, Reid D, Warsh J, West ME. Getting Bundled Payments Right in Health Care. Harvard Business Review. Available at: https://hbr.org/2015/10/getting-bundled-paymentsright-in-health-care ->. Accessed August 2018

18 Baggot D. Top 10 Considerations for Clinical Service line Leaders. GE Healthcare. Available at: https://uscan.gehealthcarepartners. com/insight-detail/top-10-considerations-for-strategic-planning-in-un ->. Accessed August 2018

19 Schneller ES, Smeltzer LR. Repositioning supply chain in health care systems. In Schneller ES, Burns LR, Smeltzer LR, eds. Strategic Management of the Healthcare Supply Chain. San Francisco, CA: Jossey-Bass; 2006:277-298

20 Kaplan RS. Improving value with TDABC. Healthc Financ Manage 2014;68(06):76-83 